\title{
Parkinson's Disease: Gene Therapies
}

\author{
Philippe G. Coune, Bernard L. Schneider, and Patrick Aebischer \\ Neurodegenerative Studies Laboratory, Brain Mind Institute, Ecole Polytechnique Fédérale \\ de Lausanne (EPFL), CH-1015 Lausanne, Switzerland \\ Correspondence: patrick.aebischer@epfl.ch
}

With the recent development of effective gene delivery systems, gene therapy for the central nervous system is finding novel applications. Here, we review existing viral vectors and discuss gene therapy strategies that have been proposed for Parkinson's disease. To date, most of the clinical trials were based on viral vectors to deliver therapeutic transgenes to neurons within the basal ganglia. Initial trials used genes to relieve the major motor symptoms caused by nigrostriatal degeneration. Although these new genetic approaches still need to prove more effective than existing symptomatic treatments, there is a need for disease-modifying strategies. The investigation of the genetic factors implicated in Parkinson's disease is providing precious insights in disease pathology that, combined with innovative gene delivery systems, will hopefully offer novel opportunities for gene therapy interventions to slow down, or even halt disease progression.

Parkire rkinson's disease (PD) presents several features that make it an ideal target for gene therapy. PD is a progressive, long-lasting neurodegenerative disease that is not adequately treated with pharmacological approaches. Furthermore, the cause of the major motor symptoms is well defined, and associated with dysfunctions in brain nuclei that can be effectively targeted with viral vector technologies for gene transfer to brain cells. Therefore, part of the gene therapy strategies aim at increasing the efficacy and at reducing the side effects of the current pharmacological and surgical treatments.

Besides the possibility to correct motor symptoms, our understanding of the genetic causes of PD has made considerable progress during the last decade. Consequently, several strategies based on the delivery of neuroprotective genes to the basal ganglia nuclei are currently investigated to possibly halt disease progression.

\section{PRINCIPLE AND TOOLS}

Gene therapy aims at treating disease by genetically modifying populations of cells that are either directly functionally impaired or capable of relieving the disease symptoms. These genetic modifications can either increase or reduce the expression of specific genes or gene sets, or even restore the normal function of the product of these genes. In human therapeutic applications, these modifications can only be made on somatic cells and must spare the germline for ethical reasons. A distinction is made between in vivo gene therapy, i.e., the direct genetic modification of cells inside the body, and ex vivo gene

Editor: Serge Przedborski

Additional Perspectives on Parkinson's Disease available at www.perspectivesinmedicine.org

Copyright (C) 2012 Cold Spring Harbor Laboratory Press; all rights reserved; doi: 10.1101/cshperspect.a009431

Cite this article as Cold Spring Harb Perspect Med 2012;2:a009431 
P. Coune et al.

therapy, which is based on the genetic modification of cells maintained in culture prior to implantation in the patient.

Various methods have been developed for gene delivery to the target cells, which include viral vectors, and nonviral systems. Nonviral methods, which are marginally used for gene transfer to the central nervous system (CNS), comprise chemical and physical methods, such as gene gun or electroporation. In vivo gene transfer using viral vectors is today the most commonly used approach in the CNS, with 20 trials listed in 2010 ( Lim et al. 2010). This approach takes advantage of the viruses' ability to deliver their genetic material to target cells, including nondividing cells, and to induce long-term transgene expression. As most of the cells in the CNS, including neurons, are postmitotic, the ability of viral vectors to transduce nondividing cells is of crucial importance in the context of PD gene therapy.

Viral vectors are engineered from wild-type viruses by removing the genes essential to their replication from their genome. The removed genetic information is provided in trans for vector production, and is not incorporated inside the particles. The vectors are therefore able to infect cells and transfer their genetic material into the nucleus, but they are unable to replicate themselves in the host cells. This aspect is critical for vector biosafety, as it eliminates virus pathogenicity and prevents uncontrolled spreading of transgene delivery caused by vector replication in the host organism. Although viral gene delivery systems lead to irreversible genetic modifications within the patient tissues, currently available vectors allow for efficient and stable transgene expression in a broad range of cellular types across the brain. Several types of vectors have been developed, differing by their packaging capacity, tropism, and immunogenicity. Here we will focus on vectors derived from adeno-associated virus (AAV) and lentivirus, as they are the only ones that have reached the clinic for CNS gene therapy trials.

\section{Lentivectors}

Lentiviruses are enveloped viruses from the Retroviridae family. Their genome consists of single-stranded RNA that encodes structural proteins, and cis-acting factors controlling the packaging, reverse transcription, nuclear localization and integration of the viral genome in the host cell genome. Lentivectors have been developed from primate lentiviruses, such as the wild-type human immunodeficiency virus type 1 (HIV-1) and nonprimate lentiviruses, such as the equine infectious anemia virus (EIAV), by progressively removing most of the viral genes from the vector genome to limit the risk of producing replication-competent viral particles (Naldini et al. 1996b; Zufferey et al. 1997, 1998; Dull et al. 1998; Olsen 1998). Depending on the production system employed, the viral genes gag, pol, tat, and rev, which are necessary to the production of infectious viral particles, are provided in trans using separate plasmids cotransfected in the packaging cells. The maximal packaging capacity of lentivectors is $18 \mathrm{~kb}$, but the most efficient packaging is obtained with genomes in the range of 6 to $9 \mathrm{~kb}$ (Kumar et al. 2001). To target neurons and obtain highly concentrated vector suspensions, lentivectors are typically pseudotyped by replacing the wild-type envelope with the envelope of the vesicular stomatitis virus G (VSV$\mathrm{G})$. The resulting pseudotyped vectors have a broad cell tropism including neuronal and glial cells (Naldini et al. 1996a). Lentivectors have the ability to integrate into the host cell genome and lead to stable transgene expression. This feature is particularly useful for ex vivo gene therapy applications: cell lines or stem cells can be stably transduced using lentivectors and transgene expression carefully characterized prior to implantation. Because integration occurs at random sites, there is a risk for insertional mutagenesis that has to be considered for in vivo gene therapy. However, a study using lentivectors in a mouse strain highly susceptible to tumor formation did not reveal any increase in tumor occurrence (Montini et al. 2006), and an on-going clinical trial using lentivectors in PD did not report any evidence of tumorigenicity yet (Lim et al. 2010). To address this potential problem, nonintegrating lentiviral vectors have been developed to improve the vector safety profile (Rahim et al. 2009). 


\section{AAV-Based Vectors}

Vectors derived from adeno-associated viruses $(\mathrm{AAV})$ are the most frequent type of vectors used in clinical trials for CNS diseases. AAVs are small nonenveloped viruses of the parvoviridae family. The $4.7 \mathrm{~kb}$ AAV genome is composed of single-stranded DNA encoding four proteins essential for replication and packaging (rep gene), and three capsid proteins (cap gene), surrounded by two inverted terminal repeats (ITR). Even in their wild-type form, AAVs depend on the coinfection with a helper virus, such as adenovirus or herpes virus, for efficient replication inside the host cells. As AAVs are considered nonpathogenic in humans, and their capsid proteins induce only mild immune reactions (Büning et al. 2008), they are prime candidates for gene therapy. However, $90 \%$ of the population has been exposed to AAV serotype 2 , and therefore has preexisting antibodies that will neutralize AAV2-based vectors and reduce their transduction efficacy (Moskalenko et al. 2000). Genetic modifications of the capsid proteins can disrupt the immunogenic epitopes and possibly circumvent this limitation (Maersch et al. 2010). In addition, the CNS benefits from a relative immune privilege, which reduces the risk of neutralizing activity.

Viral vectors have been derived from wildtype $\mathrm{AAV}$ s by the deletion of all the viral sequences except the ITRs. Consequently, AAV vectors cannot replicate and do not express any viral proteins, which further reduces their immunogenicity. During the production of AAV vectors, rep and cap are typically provided in trans using a helper plasmid system cotransfected with the transgene plasmid in presence of an adenovirus (Samulski et al. 1989). More recently, "helper virus-free" systems have been developed, in which the adenoviral helper activity is also provided via the recombinant helper plasmid (Grimm et al. 2003). After transfection, recombinant AAV particles are harvested by lysis of the packaging cells, purified, and finally concentrated in suspensions that typically contain $10^{12}-10^{14}$ particles per ml.

AAV vector particles can efficiently infect a broad range of cells, including postmitotic cells, and display a good neuronal tropism (Paterna et al. 2004). They enter the host cell though receptor-mediated endocytosis, and are translocated to the nucleus where their genome is converted into double-stranded DNA. Although wild-type AAVs preferentially integrate to the human genome at a specific locus on chromosome 19, termed AAVS1 (Samulski et al. 1991; Huser et al. 2010), recombinant AAV vectors form stable episomal concatemers in the absence of the Rep protein. In postmitotic cells, episomal AAV genomes provide long-term ( $>1 \mathrm{yr}$ ) transgene expression. The low rate of integration of recombinant $\mathrm{AAV}$ vectors is considered an asset in their safety profile, as it limits the occurrence of insertional mutagenesis.

There are currently more than $100 \mathrm{AAV}$ serotypes described from different animal species (Kwon and Schaffer 2008). These serotypes mainly differ by the protein composition of the capsid. As AAV tropism is mainly determined by the properties of the capsid, it is possible to create pseudotyped vectors with various tropisms by packaging the genome of a particular serotype (most often AAV2) into a capsid derived from another serotype.

Overall, AAV vectors represent ideal vectors to deliver genes in the CNS. They present a very good safety profile, and provide efficient transduction and durable expression of neurons. The main limitation of AAV is the limited packaging capacity $(4.7 \mathrm{~kb})$ that precludes the integration of large genes, or multiple expression cassettes.

\section{SYMPTOMATIC THERAPIES}

Current pharmacological and surgical therapies for PD all aim at compensating for the basal ganglia dysfunction caused by the degeneration of the dopaminergic neurons from the substantia nigra pars compacta (SNpc). L-dopa therapy increases dopamine production in the remaining nigral neurons and thereby compensates for the lack of neurotransmitter in the striatum. On the other hand, deep brain electrical stimulation (DBS) modulates the overactivity of the subthalamic nucleus consecutive to the loss of dopamine signaling in the striatum. Although both approaches provide symptomatic relief to 
P. Coune et al.

PD patients, they also present a number of drawbacks. Gene therapy approaches have been investigated for their ability to similarly correct motor symptoms and possibly reduce the occurrence of adverse effects associated with the existing symptomatic treatments.

\section{Enzyme Replacement Strategies}

Similar to L-dopa-therapy, enzyme replacement therapies aim at compensating for the decrease of dopamine release resulting from the degeneration of the nigrostriatal dopaminergic neurons. These approaches are based on the transfer of genes encoding the enzymes required for dopamine synthesis into the striatal GABAergic neurons. Endowed with these enzymes, the GABAergic neurons are able to ectopically synthetize dopamine that will be released in the striatum.

Dopamine is synthesized from tyrosine, which is provided either by the nutrition or through the conversion of phenylalanine into tyrosine by the enzyme phenylalanine hydroxylase. Tyrosine is next hydroxylated into L-dopa by tyrosine hydroxylase $(\mathrm{TH})$ and finally, L-dopa is converted into dopamine by the aromatic amino acid decarboxylase (AADC). TH activity is the limiting factor in dopamine biosynthesis, and requires a cofactor, tetrahydrobiopterine (BH4), the synthesis of which requires the enzyme GTP-cyclohydrolase-1 (GCH-1) (Kettler et al. 1974). Synthetized dopamine is transferred and concentrated in storage vesicles by the vesicular monoamine transporter VMAT2.

Although L-dopa therapy has been the mainstay of PD therapy since 1969 (Cotzias et al. 1969), its efficacy is limited by major side effects. Because dopaminergic drugs diffuse poorly into the CNS, they need to be systemically administered at high dose with an increased risk of peripheral adverse effects. At advanced stages of the disease, discontinuous L-dopa therapy is associated with the apparition of debilitating dyskinesia presumably linked to fluctuations in the brain concentration of L-dopa. Gene delivery of the enzymes needed for dopamine synthesis could provide a continuous ectopic production of dopamine in the striatum, which may reduce the apparition of dyskinesia and limit the side effects caused by elevated dopamine levels outside the basal ganglia (Fig. 1).

\section{Full Ectopic Dopamine Synthesis}

A possible approach is to deliver the genes $\mathrm{TH}$, AADC, and GCH1 to medium spiny neurons (MSN) in the striatum, to induce ectopic dopamine synthesis from tyrosine. This strategy has been shown to successfully increase striatal dopamine and correct motor deficits in 6-OHDA lesioned rats (Shen et al. 2000; Sun et al. 2003) and MPTP-treated cynomolgus macaque monkeys (Muramatsu et al.2002). However, elevated concentrations of dopamine can negatively regulate TH activity via a feedback loop that may limit the capacity for ectopic dopamine synthesis. This caveat can be circumvented by the use of a constitutively active truncated version of TH (Moffat et al. 1997).

A tri-cistronic EIAV-based lentivector coding for AADC and GCH1 and a truncated form of TH, has been developed by Oxford BioMedica under the name of ProSavin and successfully tested in 6-OHDA-lesioned rats (Azzouz et al. 2002). A study in MPTP-treated macaque monkeys (Jarraya et al. 2009) showed that ProSavin treatment does not only reduce motor impairment, but also leads to a drastic reduction of dyskinesia when compared to conventional L-dopa-therapy. The safety, efficacy, and dose evaluation of ProSavin are currently under evaluation in a phase I/II clinical trial.

\section{Ectopic L-dopa Conversion}

Genetic enzyme replacement therapy can also be used to increase the efficacy of pharmacological L-dopa therapy. The degeneration of the nigral dopaminergic neurons leads to a decrease in striatal AADC activity, which is essential for L-dopa conversion into dopamine (Ichinose et al. 1994). Therefore, the efficacy of the Ldopa treatment can be eventually limited by the loss of AADC activity. Advanced PD patients could benefit from gene transfer to restore striatal AADC levels, thereby lowering the effective dose of L-dopa and limiting the side effects. 


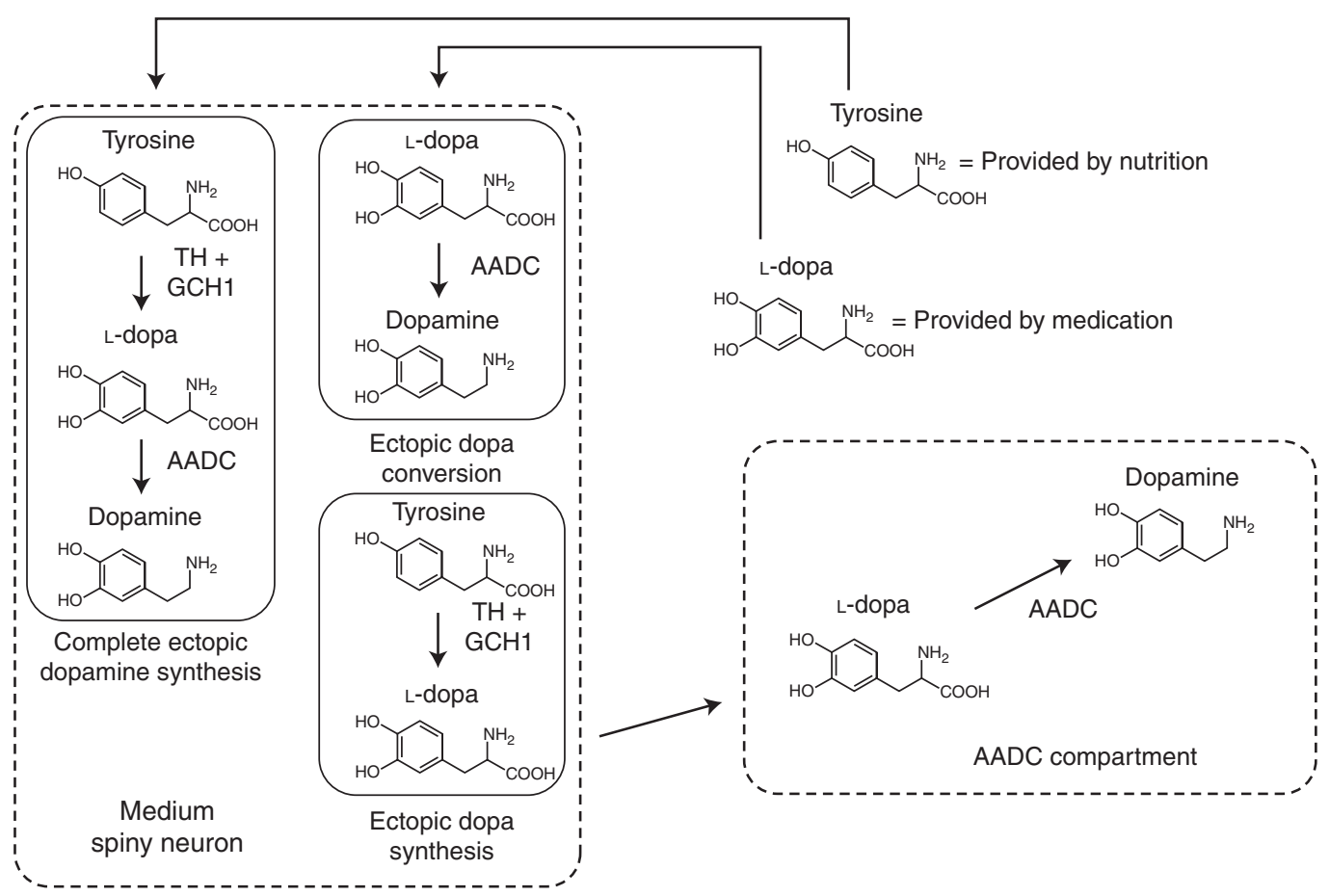

Figure 1. The different enzyme replacement therapy approaches in PD. Enzyme replacement therapies aim at compensating the decrease of striatal dopamine release caused by the degeneration of the nigral dopaminergic neurons, by inducing ectopic dopamine synthesis in the striatum.

$\mathrm{AAV}$ vectors have been designed to deliver the AADC coding sequence to the striatal MSNs, which are then able to convert the administered L-dopa into dopamine. Striatal injection of AADC-coding AAV vectors was shown to effectively and stably restore the response to L-dopa in MPTP-treated rhesus macaque monkeys (Bankiewicz et al. 2000, 2006). A phase I clinical trial (Eberling et al. 2008; Christine et al. 2009) in bilaterally infused patients did not report any significant adverse effects related to the viral vector itself, even though the stereotaxic surgery led to hemorrhages in several patients. PET imaging reported an increase of striatal AADC activity at 1 and 6 months postinjection, which was dependent on the vector dose administered and confirmed stable transgene expression. Modest clinical improvements were observed in both on- and off-states, in addition to a decrease of the effective L-dopa dose. However, because of the open design of the trial, placebo effect cannot be excluded. Importantly,
AADC striatal expression allows for a control of the gene therapy effects via the modulation of the L-dopa dosage. As systems for controlling the level of transgene expression are not currently available for human applications, such a combined approach offers some advantages overother nonregulated gene therapy approaches for PD.

Strategies aiming at chronic ectopic dopamine production in the striatum may cause detrimental effects over time. Indeed, these gene therapy approaches target GABAergic striatal neurons that are unable to store dopamine into vesicles for synaptic release. Ectopic dopamine synthesis may therefore lead to uncontrolled extracellular or cytosolic levels of dopamine, often associated with chronic oxidative stress. Increase in both cytosolic (Chen et al. 2008) and extracellular (Cyr et al. 2003) levels of dopamine have been shown to lead to the degeneration of the striatal neurons. Therefore, therapeutic strategies should be cautiously designed to avoid excessive striatal dopamine concentration. 
P. Coune et al.

\section{Ectopic L-dopa Synthesis}

An alternative gene therapy approach aims at ectopically producing L-dopa in the striatum by transfer of the $\mathrm{TH}$ and $\mathrm{GCH} 1$ genes into MSNs. Endogenous AADC activity can convert the L-dopa produced in the striatum into dopamine.

This strategy has been shown to improve motor deficits in rats presenting partial (Kirik et al. 2002) and total 6-OHDA-induced nigrostriatal denervation (Björklund et al. 2010), and to reduce dyskinesia caused by intermittent administrations of L-dopa (Carlsson et al. 2005). Interestingly, ${ }^{11} \mathrm{C}$-raclopride positron emission tomography (PET) analyses indicates that functional recovery is correlated with the reconstitution of a functional pool of endogenous dopamine in the striatum (Leriche et al. 2009). This finding is surprising considering that there is no evidence that dopamine storage and release mechanisms are restored. Studies in nonhuman primates are currently ongoing to further assess the safety and efficacy of this gene therapy strategy.

The loss of AADC activity caused by the progression of nigrostriatal neurodegeneration may limit the long-term efficacy of this approach. However, striatal serotoninergic terminals projecting from the raphe nucleus do not degenerate to the same extent as dopaminergic terminals in $\mathrm{PD}$ (Kish et al. 2008). As they express both AADC and VMAT2, they are likely to provide a disease-resistant source of AADC activity for L-dopa conversion into dopamine. In addition, preclinical studies have shown that even in case of serotoninergic denervation, there is enough remaining striatal AADC activity for dopamine production. Although the exact nature of that third AADC compartment is currently unknown, it may include striatal neurons and nonneuronal cells, such as astrocytes (Björklund et al. 2010).

\section{Glutamic Acid Decarboxylase Expression in the Subthalamic Nucleus}

In $\mathrm{PD}$, the loss of dopamine signaling in the striatum affects the activity of several deep brain nuclei. In particular, striatal dopamine depletion leads, via the "indirect" pathway, to a de- crease in the inhibitory control exerted by the external segment of the globus pallidus (GPe) on the subthalamic nucleus (STN). The subsequent lack of inhibition of the STN affects the output of the basal ganglia circuitry, thereby causing impairments in motor functions. DBS is based on high frequency electrical stimulations applied to the STN to interfere with its abnormally high activity. By doing so, DBS can significantly improve the main motor parkinsonian symptoms.

In 2002, Luo et al. described a gene therapy approach aiming at modulating STN activity (Luo et al.2002) by delivering the genes glutamic acid decarboxylase (GAD), the rate-limiting enzyme for the synthesis of GABA. Using an AAV vector, the approach targets the glutamatergic neurons of the STN. The neurons transduced with GAD synthesize and release GABA in an activity-dependent manner. The modified neurotransmitter pattern in STN projections leads to an inhibitory bias in the substantia nigra pars reticulata $(\mathrm{SNr})$ and regulates the firing rates of basal ganglia nuclei in 6-OHDA-lesioned rats (Lee et al. 2005). These effects on the biochemical and electrophysiological properties of the STN-to-SNr projections improve the 6-OHDA-induced motor deficits in rats as a function of GAD expression levels (Luo et al. 2002; Lee et al. 2005). These findings were later confirmed in MPTP-treated rhesus monkeys. ${ }^{18}$ F-fluorodeoxyglucose (FDG) PET investigation showed that the improvement in clinical ratings is correlated with an increase in glucose metabolism in the ipsilateral motor cortex (Emborg et al. 2007). However, although GAD expression in the STN of 6-OHDA lesioned rats had a neuroprotective effect (Luo et al. 2002), no such effect was observed in the MPTP-treated monkeys. Importantly, these preclinical studies did not report any adverse effects in animal models.

Clinical studies were initiated in PD patients. In mammals, there are two isoforms of GAD, GAD65, and GAD67, which are both expressed in most GABAergic neurons in the brain (LeWitt et al. 2011). As these two isoforms displayed variable relative efficacy in rats and primate models of $\mathrm{PD}$, it was chosen to conduct human trials 
using a combination of two AAV2 vectors, each coding for one of these isoforms.

An open-label nonrandomized stage I study investigated the safety and tolerability of unilateral subthalamic injection of AAV2-GAD65/67 in 12 patients (Kaplitt et al. 2007). Using three vector doses, no adverse effects related to the procedure and no change in the patients' immunity against $\mathrm{AAV}$ or GAD were reported after 12 months. As reflected by UPDRS ratings of the contralateral limb, mild clinical improvements were found in both on- and off-states as soon as 3 months postsurgery, persisting for 12 months. FDG-PET analysis revealed that GAD expression in the STN corrects the thalamic hypermetabolism associated with $\mathrm{PD}$, and increases metabolic activity in the ipsilateral motor cortical regions (Feigin et al. 2007).

Although the contribution of the placebo effect remained unclear in the phase I clinical trial, this first application to humans confirmed that the procedure was safe. A phase II randomized, multicentric trial was therefore conducted to assess treatment efficacy. The trial involved 16 patients bilaterally infused with AAV2-GAD65/ 67 and 21 sham-operated patients, monitored for over 6 months. At the end of the trial, no major adverse effects related to the operation were reported, and patients displayed a modest but significant improvement of the UPDRS motor score (LeWitt et al. 2011).

Overall, these trials have confirmed the safety of the GAD gene transfer approach in the STN, and reported beneficial clinical effects. However, the improvements obtained have been so far modest-therefore, this approach should be compared with DBS in terms of safety and efficacy before any large-scale application could be envisioned.

In conclusion, the exploration of symptomatic gene therapies for PD has provided encouraging, preclinical and clinical results and has showed that current viral vectors technology allow for safe gene delivery within the basal ganglia nuclei. The availability of safe and efficient vectors is crucial to the ultimate goal of PD gene therapy: the development of therapies that would interfere with the processes underlying the disease.

\section{DISEASE-MODIFYING APPROACHES}

The main therapies available for the treatment of PD aim at restoring dopamine levels or correcting the functional perturbations of the basal ganglia caused by dopamine loss. However, these symptomatic therapies do not slow down disease progression, and their efficacy therefore declines over time. During the last decade, the discovery of genes linked to familial forms of PD has dramatically improved our understanding of the possible molecular causes of neurodegeneration.

Based on these findings, novel approaches have been proposed to possibly protect neuronal functions and halt disease progression. In this context, gene therapy offers an attractive alternative to deliver genetic information in the CNS and chronically provide the needed neuroprotective effects. Here we will discuss the use of neurotrophic factors to support the function and survival of nigral dopaminergic neurons, as well as therapeutic approaches to correct the genetic defects associated with familial forms of PD.

\section{Neurotrophic Factors: GDNF}

Neurotrophic factors are secreted proteins playing essential roles in the differentiation, growth, and survival of neuronal cells. In particular, the glial cell line-derived neurotrophic factor (GDNF), a member of the transforming growth factor (TGF)- $\beta$ superfamily, has emerged as a powerful factor to protect the dopaminergic neuronal function and has therefore been intensely investigated as a promising target for PD therapy. GDNF was identified in 1993 for its potent trophic activity on dopaminergic neurons in vitro (Lin et al. 1993). Since then, GDNF has been shown to promote axonal sprouting in vivo (Beck et al. 1995) and to be essential for the survival of dopaminergic neurons in the adult brain (Pascual et al. 2008).

\section{Direct GDNF Injections}

As the recombinant protein GDNF does not cross the human blood-brain barrier (Deierborg et al. 2008), it is crucial to find alternatives to systemic administration for PD treatment. The 
P. Coune et al.

local delivery of recombinant GDNF protein into CNS has been investigated. Direct injections, or infusion of GDNF using minipumps into the striatum, midbrain, or ventricles provided encouraging results in toxin-based rodent and primate models of PD (Kearns and Gash 1995; Sauer et al. 1995; Grondin et al. 2002, 2003; Ai et al. 2003). Notably, it has been found that GDNF can induce the sprouting of dopaminergic axons near the site of GDNF delivery (Rosenblad et al. 1999; Kirik et al. 2000). Based on the preclinical results, a randomized doubleblind clinical study was initiated using intracerebroventricular GDNF infusion (Nutt et al. 2003). The results were disappointing, with no clinical improvement and adverse effects, including anorexia. The postmortem analysis of one of the participant confirmed the absence of neuroprotection and revealed the absence of GDNF diffusion into the brain parenchyma (Kordower et al. 1999). Therefore, it appeared essential to change the mode of GDNF delivery. Indeed, a subsequent pilot study using striatal infusion with a minipump system reported positive clinical results (Gill et al. 2003). However, a double-blind phase II clinical trial run by Amgen, failed to confirm these results, and the company decided to abandon further clinical investigation of direction GDNF infusion in the CNS. Nevertheless, these trials provided a strong rationale for gene therapy as a potential alternative to the intraparenchymal delivery of recombinant neurotrophic factors.

\section{In Vivo GDNF Gene Delivery}

In contrast to the delivery of the recombinant protein, gene transfer allows for a constant and local administration of GDNF, which limits the risks of side effects associated with broad distribution of this factor, such as loss of weight and allodynia (Hoane et al. 1999). As genetically modified cells continuously synthesize GDNF, this approach would avoid protein stability issues and the potential need for repetitive interventions to inject recombinant GDNF or reload implanted minipumps.

Several in-vivo studies have been conducted in toxin-based mice and rat models of PD using adenovirus, lentivirus and AAV-based vectors to express GDNF in the striatum or the SNpc (for review, see Deierborg et al. 2008). The delivery of the GDNF gene in both brain areas leads to a reduction of dopaminergic cells loss and to behavioral recovery. The beneficial effect of viral GDNF expression on nigrostriatal degeneration and motor deficits was confirmed in MPTPtreated rhesus monkeys (Kordower et al. 2000). However, the toxin-based models used to initially validate GDNF neuroprotective effects do not provide a definite answer. The 6-OHDA and MPTP toxins induce an acute degeneration of the nigrostriatal system, which is mainly caused by the production of reactive oxygen species, and fails to replicate the complex pathogenic mechanisms involved in genetic and sporadic forms of $\mathrm{PD}$.

GDNF gene delivery has also been successfully evaluated in aged monkeys, a more physiological model that displays naturally occurring mild reduction of striatal dopamine and motor deficits (Kordower et al. 2000; Palfi et al. 2002; Johnston et al. 2009). Importantly, the effect of GDNF has also been investigated in a rat genetic model of PD based on the nigral overexpression of wild-type and mutated forms of $\alpha$-synuclein using lentiviral (Lo Bianco et al. 2004a) and AAV vectors (Decressac et al. 2011). Surprisingly, GDNF fails to provide any neuroprotective effect or induce striatal axonal sprouting in nigral neurons overexpressing $\alpha$ synuclein for reasons that remain to be elucidated. Although the effect of GDNF gene therapy is still investigated preclinically, two clinical trials have been conducted with an AAV2 vector expressing the neurotrophic factor neurturin, a close homolog of GDNF. Preclinical studies showed that intrastriatal injections of the AAV2neurturin vector protect nigral neurons from 6-OHDA-induced degeneration and preserves animal motor behavior (Gasmi et al. 2007a,b). A study in MPTP-treated monkeys reported motor dysfunction prevention and confirmed neurturin neuroprotective effects (Kordower et al. 2006). Based on these encouraging results, the bilateral intra-putaminal injection of the AAV2neuturin (CERE-120) vector was evaluated for safety and efficacy in an open label phase I 
clinical trial initiated by Ceregene (Marks et al. 2008). The monitoring of 12 treated PD patients did not reveal any serious adverse effects, and showed a marked clinical improvement in offmedication symptoms. However, the doubleblind randomized phase II clinical study that followed with 58 PD patients (Marks et al. 2010) did not reveal any significant beneficial effects of AAV2-neurturin against the control group of patients who received sham surgery. As a possible clue for the lack of effect, postmortem analysis of PD brain tissue from the AAV2-neurturin study showed neurturin expression only in the striatum, in contrast to a previous successful study in monkeys in which the retrograde transduction of nigral dopaminergic cell bodies was observed (Bartus et al. 2011).

Using viral vectors for the delivery of neurotrophic factors, there is a distinct risk that viral particles could diffuse away from the site of injection and elicit ectopic GDNF expression, which unpredictable consequences. Because of these safety concerns, alternative systems for ex vivo gene transfer have been explored. The implantation of genetically engineered stem cells (Akerud et al. 2001; Park 2001) or astrocytes (Cunningham and Su 2002) has been proposed. To further improve the safety of the approach and protect the grafted cells from potential host immune reactions, it is possible to implant cells genetically engineered for GDNF expression within a permeable polymer capsule (Tseng et al. 1997; Kishima et al. 2004; Sajadi et al. 2006). However, the efficacy of these approaches has not been investigated in PD patients yet.

In conclusion, the potential regenerative and neuroprotective effects of neurotrophic factors justify further investigation in PD. However, it is essential to evaluate the efficacy of this approach on the genetic factors of PD.

\section{Gene Therapy Based on the Genetic Causes of PD}

In the last decade, several genes implicated either in the Mendelian inheritance of PD or as risk factors for sporadic PD have been identified. These findings have dramatically changed our understanding of the disease process and provide new clues for genetic strategies that aim at slowing down the degeneration of vulnerable populations of neurons, in both familial and sporadic forms of PD.

\section{$\alpha$-Synuclein}

The small protein $\alpha$-synuclein is considered as a major actor in both sporadic and familial cases of PD. Missense mutations in the $\alpha$-synuclein coding sequence were initially found in rare families with autosomal dominant PD. Interestingly, similar cases of PD were associated with polymorphisms in the $\alpha$-synuclein promoter (Maraganore et al. 2006), and multiplications of the locus carrying the $\alpha$-synuclein gene (Singleton et al.2003; Nishioka et al. 2006). This last finding clearly links certain forms of PD with the expression level of the protein. One can therefore assume that strategies to down-regulate $\alpha$-synuclein expression may impact on the disease process. Several viral vector-based gene delivery systems have been explored to interfere with $\alpha$ synuclein expression. They mainly rely on RNA interference (RNAi) to selectively destabilize the $\alpha$-synuclein mRNA and/or block protein translation, via the transgenic expression of short hairpin RNAs (shRNA), or micro RNAs (miRNA) directed against the $\alpha$-synuclein mRNA sequence. An alternative approach based on the $\mathrm{AAV}$-mediated delivery of an anti- $\alpha$-synuclein ribozyme has also been investigated both in vitro and in vivo (Hayashita-Kinoh et al. 2006).

RNAi has been shown to successfully reduce the level of both endogenous or overexpressed $\alpha$ synuclein, either in vitro (Fountaine and WadeMartins 2007; Junn et al. 2009) or in vivo (Sapru et al. 2006; McCormack et al. 2010). In vitro silencing of A53T $\alpha$-synuclein in NS20Y cells was found to decrease proteasome impairment caused by $\alpha$-synuclein and increase the cell resistance to oxidative stress (Junn et al. 2009) supporting potential protective effect of this approach.

However, a recent study reported that knockdown of endogenous $\alpha$-synuclein in the adult rat SN leads to the degeneration of nigral dopaminergic neurons and motor deficits (Gorbatyuk et al. 2010). Although the mechanisms underly- 
P. Coune et al.

ing this effect remain unclear, it appears that extent of neurodegeneration correlates with the degree of $\alpha$-synuclein silencing. Considering that the normal function of $\alpha$-synuclein is still poorly understood, the potential consequences of uncontrolled $\alpha$-synuclein silencing should be carefully addressed, as the near complete loss of $\alpha$ synuclein may have negative effects on neuronal function and survival. Although challenging, it may be important to devise strategies to genetically control the degree of $\alpha$-synuclein silencing to safely implement this approach in $\mathrm{PD}$ patients.

Gene therapy could also provide essential tools for PD cell therapy. Induced pluripotent stem cells (iPSC) are stem cells derived from patients somatic cells that can be differentiated into dopaminergic neurons (Soldner et al. 2009). These dopaminergic cells could then be implanted in the striatum of PD patients to compensate for the nigral cell loss occurring during PD. However, as these cells are derived from PD patients, there is a distinct risk that they could carry mutations perpetuating the pathology once grafted in the patients. This issue has been addressed in a recent study reporting the generation of iPSC in which disease-causing point mutations have been corrected using zinc finger nucleases (Soldner et al. 2011).

\section{Parkin}

Parkin has been linked with PD by the discovery of mutations associated with autosomal recessive juvenile parkinsonism (AR-JP), an early onset form of PD with typical symptoms and pathology and very slow disease progression (Kitada et al. 1998). Parkin is an E3 ubiquitin ligase that polyubiquitylates proteins destined for degradation by the proteasome (Shimura et al. 2000). AR-JP mutations lead to partial or complete loss of the protein function (Shimura et al. 2000), and therefore to the accumulation of potentially toxic substrate proteins. In addition to protein ubiquitylation, there is also evidence for beneficial effects of Parkin expression on oxidative stress levels (Hyun et al. 2002), and more recently, on mitochondrial homeostasis, as illustrated by the Parkin-induced autophagic elimination of dysfunctional mitochondria (Narendra et al. 2008). Therefore, Parkin appears as potential neuroprotective agent with a broad mode of action, which may contribute to neuronal resistance to various stressors potentially implicated in sporadic forms of the disease as well.

In rats with a partial unilateral 6-OHDA lesion, a lentiviral vector encoding Parkin had a significant neuroprotective effect, leading to a correction of motor asymmetry for 20 weeks (Vercammen et al. 2006). Using a more severe 6-OHDA-induced lesion, a subsequent study using an AAV vector did not confirm the neuronal protection, but reported a decrease in druginduced rotametry and spontaneous behavior in conditions of Parkin overexpression (Manfredsson et al. 2007). It was suggested that Parkin could improve motor function via increased levels of tyrosine hydroxylase and striatal dopamine, thereby enhancing dopamine striatal neurotransmission. In MPTP-treated mice, an AAV vector for Parkin expression was reported to induce significant neuroprotection (Paterna et al. 2007).

Parkin expression has further proved neuroprotective in genetic animal models of PD. In Drosophila, Parkin expression has been shown to reduce dopaminergic neurons degeneration induced by the Parkin substrate PaelR (Yang et al. 2003). Studies conducted in rats using lentiviral (Lo Bianco et al. 2004b) and AAV (Yamada et al. 2005) vectors showed that Parkin overexpression significantly reduces the $\alpha$-synuclein-induced nigrostriatal degeneration, and leads to behavioral recovery (Yamada et al. 2005). The only primate study conducted yet did not report a protective effect of Parkin against the $\alpha$-synuclein-induced loss of dopaminergic neurons in the $\mathrm{SNpc}$ (Yasuda et al. 2007). However, the study only included two macaque monkeys and was limited by the only partial transduction of the dopaminergic nigral neurons achieved using an AAV vector.

Overall, viral vectors for Parkin expression have shown neuroprotective effects in various animal models of PD. Targeting the subset of patients afflicted by AR-JP associated to Parkin deficiency appears as an obvious strategy for the 
clinical application of this etiologic gene therapy approach. However, despite an early onset, the Parkin-linked form of the disease has a very slow progression (Khan et al. 2002), with a good response to L-dopa therapy. These features clearly raise the bar for gene therapy application. It is therefore important to further explore the function of Parkin and perform more extensive preclinical studies in nonhuman primates, to determine the possible detrimental effects of long-term Parkin overexpression.

\section{CONCLUDING REMARKS}

In the past decade, PD has been the main CNS application for gene therapy strategies. This is in large part because of the fact that viral vectors can now efficiently target the neuronal populations clustered within brain nuclei that are responsible for the major symptoms of PD. Indeed, the viral vector technology has made great progress. Novel vectors are capable of inducing long-term expression in populations of neurons spread over millimeters to centimeters of brain parenchyma. With the new recombinant technologies, the vectors are safer and, in the absence of any viral protein expression, they avoid detrimental host immune reactions.

Until now, gene therapy has mainly reached clinical trials for the treatment of PD with the rationale of improving the treatments that target the motor symptoms (Fig. 2). The vectors can transfer genetic information to the brain and therefore allow for long-term exposure to factors that would otherwise not cross the blood-brain barrier. In addition, CNS transgene delivery is an efficient system to induce the continuous expression of enzymes involved in dopamine synthesis. By avoiding the fluctuations in brain dopamine concentrations that typically lead to side effects in PD, gene therapy offers a potential alternative to the existing pharmacological treatments. However, as L-dopa therapy and DBS already provide significant benefit, gene therapy has to prove more effective than these treatments to be considered as a reasonable alternative. Therefore, it is not obvious to adopt irreversible gene therapy strategies at an

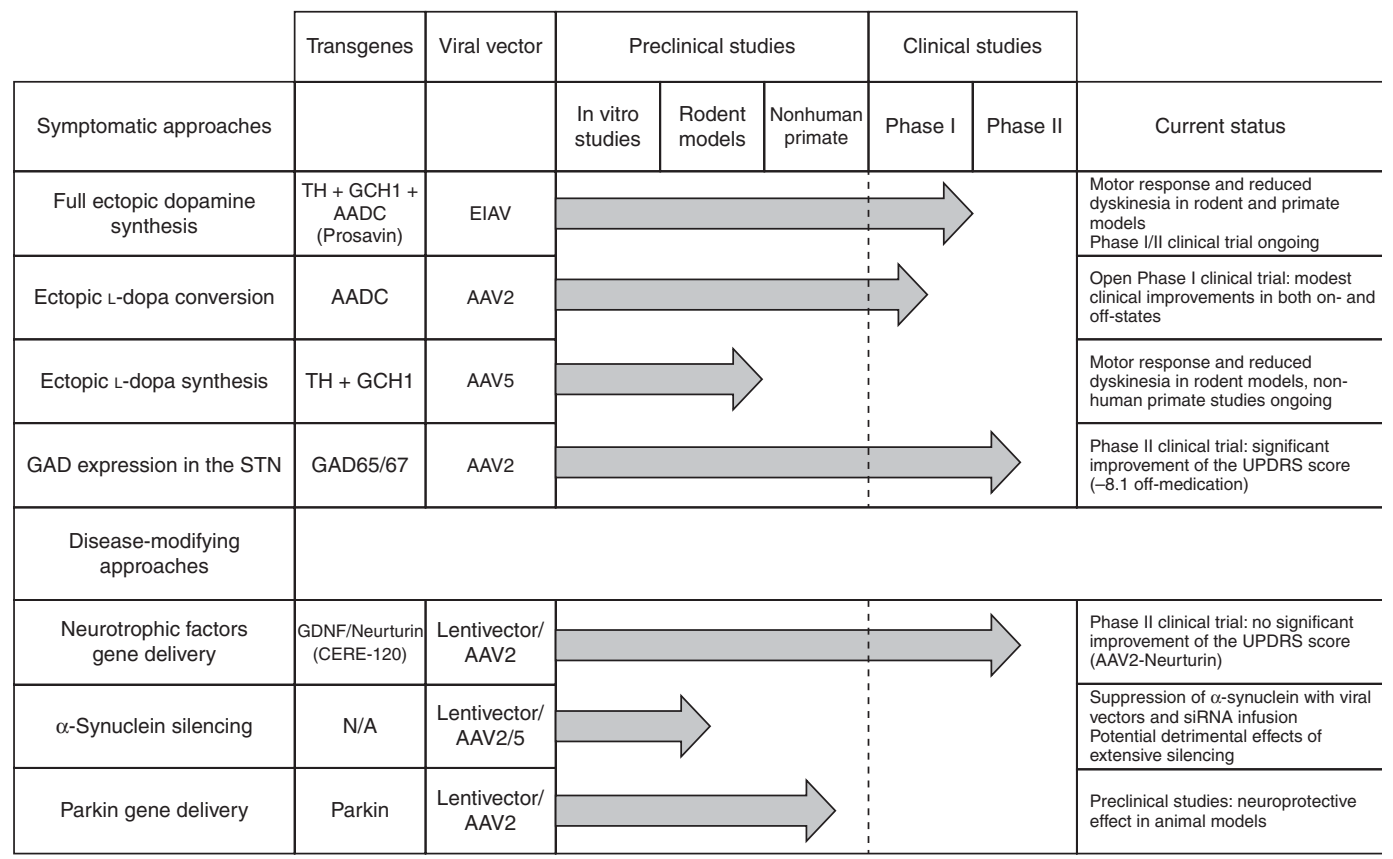

Figure 2. Current status of the different gene therapy approaches in PD. 
P. Coune et al.

early stage of the pathology, in which a significant part of the neurons still survive and the therapy has the most chance to succeed.

In the long term, identifying the causes of Parkinson's disease is a crucial challenge to prevent the disease from progressing to near total neuronal loss and untreatable dysfunctions. With the rapid progress in understanding the genetic causes of PD, the number of possible targets for gene therapy will undoubtedly increase. In addition, the development of novel viral vector systems allowing for the induction and fine regulation of transgene expression will provide the needed tools to correct the genetic defects associated with PD and/or their downstream toxic effects. Ultimately, such approaches have the potential to curb the rate of neuronal loss in diseased brain regions.

\section{ACKNOWLEDGMENTS}

This work is supported by the Swiss National Science Foundation (Grant 31003_120653).

\section{REFERENCES}

Ai Y, Markesbery W, Zhang Z, Grondin R, Elseberry D, Gerhardt GA, Gash DM. 2003. Intraputamenal infusion of GDNF in aged rhesus monkeys: Distribution and dopaminergic effects. J Comp Neurol 461: 250-261.

Akerud P, Canals JM, Snyder EY, Arenas E. 2001. Neuroprotection through delivery of glial cell line-derived neurotrophic factor by neural stem cells in a mouse model of Parkinson's disease. J Neurosci 21: 8108-8118.

Azzouz M, Martin-Rendon E, Barber RD, Mitrophanous KA, Carter EE, Rohll JB, Kingsman SM, Kingsman AJ, Mazarakis ND. 2002. Multicistronic lentiviral vectormediated striatal gene transfer of aromatic L-amino acid decarboxylase, tyrosine hydroxylase, and GTP cyclohydrolase I induces sustained transgene expression, dopamine production, and functional improvement in a rat model. J Neurosci 22: 10302-10312.

Bankiewicz KS, Eberling JL, Kohutnicka M, Jagust W, Pivirotto P, Bringas J, Cunningham J, Budinger TF, HarveyWhite J. 2000. Convection-enhanced delivery of AAV vector in parkinsonian monkeys; in vivo detection of gene expression and restoration of dopaminergic function using pro-drug approach. Exp Neurol 164: 2-14.

Bankiewicz KS, Forsayeth J, Eberling JL, Sanchez-Pernaute R, Pivirotto P, Bringas J, Herscovitch P, Carson RE, Eckelman W, Reutter B, et al. 2006. Long-term clinical improvement in MPTP-lesioned primates after gene therapy with AAV-hAADC. Mol Ther 14: 564-570.

Bartus RT, Herzog CD, Chu Y, Wilson A, Brown L, Siffert J, Johnson EM, Olanow CW, Mufson EJ, Kordower JH.
2011. Bioactivity of AAV2-neurturin gene therapy (CERE120): Differences between Parkinson's disease and nonhuman primate brains. Movement Disorders 26: 27-36.

Beck KD, Valverde J, Alexi T, Poulsen K, Moffat B, Vandlen RA, Rosenthal A, Hefti F. 1995. Mesencephalic dopaminergic neurons protected by GDNF from axotomy-induced degeneration in the adult brain. Nature 373: 339-341.

Björklund T, Carlsson T, Cederfjäll EA, Carta M, Kirik D. 2010. Optimized adeno-associated viral vector-mediated striatal DOPA delivery restores sensorimotor function and prevents dyskinesias in a model of advanced Parkinson's disease. Brain 133: 496-511.

Büning H, Perabo L, Coutelle O, Quadt-Humme S, Hallek M. 2008. Recent developments in adeno-associated virus vector technology. J Gene Med 10: 717-733.

Carlsson T, Winkler C, Burger C, Muzyczka N, Mandel RJ, Cenci A, Björklund A, Kirik D. 2005. Reversal of dyskinesias in an animal model of Parkinson's disease by continuous L-DOPA delivery using rAAV vectors. Brain 128: $559-569$.

Chen L, Ding Y, Cagniard B, Van Laar AD, Mortimer A, Chi W, Hastings TG, Kang UJ, Zhuang X. 2008. Unregulated cytosolic dopamine causes neurodegeneration associated with oxidative stress in mice. J Neurosci 28: 425-433.

Christine CW, Starr PA, Larson PS, Eberling JL, Jagust WJ, Hawkins RA, VanBrocklin HF, Wright JF, Bankiewicz KS, Aminoff MJ. 2009. Safety and tolerability of putaminal AADC gene therapy for Parkinson disease. Neurology 73: $1662-1669$.

Cotzias GC, Papavasiliou PS, Gellene R. 1969. Modification of Parkinsonism-chronic treatment with L-dopa. N Engl J Med 280: 337-345.

Cunningham LA, Su C. 2002. Astrocyte delivery of glial cell line-derived neurotrophic factor in a mouse model of Parkinson's disease. Exp Neurol 174: 230-242.

Cyr M, Beaulieu J-M, Laakso A, Sotnikova TD, Yao W-D, Bohn LM, Gainetdinov RR, Caron MG. 2003. Sustained elevation of extracellular dopamine causes motor dysfunction and selective degeneration of striatal GABAergic neurons. Proc Natl Acad Sci 100: 11035-11040.

Decressac M, Ulusoy A, Mattsson B, Georgievska B, Romero-Ramos M, Kirik D, Björklund A. 2011. GDNF fails to exert neuroprotection in a rat $\{\alpha\}$-synuclein model of Parkinson's disease. Brain 134: 2302-2311.

Deierborg T, Soulet D, Roybon L, Hall V, Brundin P. 2008. Emerging restorative treatments for Parkinson's disease. Progress Neurobiol 85: 407-432.

Dull T, Zufferey R, Kelly M, Mandel RJ, Nguyen M, Trono D, Naldini L. 1998. A third-generation lentivirus vector with a conditional packaging system. J Virol 72: 8463-8471.

Eberling JL, Jagust WJ, Christine CW, Starr P, Larson P, Bankiewicz KS, Aminoff MJ. 2008. Results from a phase I safety trial of hAADC gene therapy for Parkinson disease. Neurology 70: 1980-1983.

Emborg ME, Carbon M, Holden JE, During MJ, Ma Y, Tang C, Moirano J, Fitzsimons H, Roitberg BZ, Tuccar E, et al. 2007. Subthalamic glutamic acid decarboxylase gene therapy: Changes in motor function and cortical metabolism. J Cerebral Blood Flow Metabol 27: 501-509. 
Feigin A, Kaplitt MG, Tang C, Lin T, Mattis P, Dhawan V, During MJ, Eidelberg D. 2007. Modulation of metabolic brain networks after subthalamic gene therapy for Parkinson's disease. Proc Natl Acad Sci 104: 19559-19564.

Fountaine TM, Wade-Martins R. 2007. RNA interferencemediated knockdown of $\alpha$-synuclein protects human dopaminergic neuroblastoma cells from $\mathrm{MPP}^{+}$toxicity and reduces dopamine transport. J Neurosci Res 85: 351363.

Gasmi M, Brandon EP, Herzog CD, Wilson A, Bishop KM, Hofer EK, Cunningham JJ, Printz MA, Kordower JH, Bartus RT. 2007a. AAV2-mediated delivery of human neurturin to the rat nigrostriatal system: Long-term efficacy and tolerability of CERE-120 for Parkinson's disease Neurobiol Dis 27: 67-76.

Gasmi M, Herzog CD, Brandon EP, Cunningham JJ, Ramirez GA, Ketchum ET, Bartus RT. 2007b. Striatal delivery of neurturin by CERE-120, an AAV2 vector for the treatment of dopaminergic neuron degeneration in Parkinson's disease. Mol Ther 15: 62-68.

Gill SS, Patel NK, Hotton GR, O'Sullivan K, McCarter R, Bunnage M, Brooks DJ, Svendsen CN, Heywood P. 2003. Direct brain infusion of glial cell line-derived neurotrophic factor in Parkinson disease. Nat Med 9: 589595.

Gorbatyuk OS, Li S, Nash K, Gorbatyuk M, Lewin AS, Sullivan LF, Mandel RJ, Chen W, Meyers C, Manfredsson FP, et al. 2010. In vivo RNAi-mediated $\alpha$-synuclein silencing induces nigrostriatal degeneration. Mol Ther 18: 1450 1457.

Grimm D, Kay MA, Kleinschmidt JA. 2003. Helper virusfree, optically controllable, and two-plasmid-based production of adeno-associated virus vectors of serotypes 1 to 6. Mol Ther 7: 839-850.

Grondin R, Zhang Z, Yi A, Cass WA, Maswood N, Andersen AH, Elsberry DD, Klein MC, Gerhardt GA, Gash DM. 2002. Chronic, controlled GDNF infusion promotes structural and functional recovery in advanced parkinsonian monkeys. Brain 125: 2191-2201.

Grondin R, Cass WA, Zhang Z, Stanford JA, Gash DM, Gerhardt GA. 2003. Glial cell line-derived neurotrophic factor increases stimulus-evoked dopamine release and motor speed in aged rhesus monkeys. J Neurosci 23: 1974-1980.

Hayashita-Kinoh H, Yamada M, Yokota T, Mizuno Y, Mochizuki H. 2006. Down-regulation of $\alpha$-synuclein expression can rescue dopaminergic cells from cell death in the substantia nigra of Parkinson's disease rat model. Biochem Biophys Res Commun 341: 1088-1095.

Hoane MR, Gulwadi AG, Morrison S, Hovanesian G, Lindner MD, Tao W. 1999. Differential in vivo effects of neurturin and glial cell-line-derived neurotrophic factor. Exp Neurol 160: 235-243.

Huser D, Gogol-Doring A, Lutter T, Weger S, Winter K, Hammer EM, Cathomen T, Reinert K, Heilbronn R. 2010. Integration preferences of wildtype AAV-2 for consensus rep-binding sites at numerous loci in the human genome. PLoS Pathogens 6: e1000985.

Hyun D-H, Lee M, Hattori N, Kubo S-I, Mizuno Y, Halliwell B, Jenner P. 2002. Effect of wild-type or mutant Parkin on oxidative damage, nitric oxide, antioxidant defenses, and the proteasome. J Biol Chem 277: 28572-28577.
Ichinose H, Ohye T, Fujita K, Pantucek F, Lange K, Riederer P, Nagatsu T. 1994. Quantification of mRNA of tyrosine hydroxylase and aromatic L-amino acid decarboxylase in the substantia nigra in Parkinson's disease and schizophrenia. J Neural Transm Park Dis Dement Sect 8: 149158.

Jarraya B, Boulet S, Ralph GS, Jan C, Bonvento G, Azzouz M, Miskin JE, Shin M, Delzescaux T, Drouot X, et al. 2009. Dopamine gene therapy for Parkinson's disease in a nonhuman primate without associated dyskinesia. Sci Transl Med 1: 2ra4.

Johnston LC, Eberling J, Pivirotto P, Hadaczek P, Federoff HJ, Forsayeth J, Bankiewicz KS. 2009. Clinically relevant effects of convection-enhanced delivery of AAV2-GDNF on the dopaminergic nigrostriatal pathway in aged rhesus monkeys. Hum Gene Ther 20: 497-510.

Junn E, Lee K-W, Jeong BS, Chan TW, Im J-Y, Mouradian MM. 2009. Repression of $\alpha$-synuclein expression and toxicity by microRNA-7. Proc Natl Acad Sci 106: 1305213057.

Kaplitt MG, Feigin A, Tang C, Fitzsimons HL, Mattis P, Lawlor PA, Bland RJ, Young D, Strybing K, Eidelberg D, et al. 2007. Safety and tolerability of gene therapy with an adeno-associated virus (AAV) borne GAD gene for Parkinson's disease: An open label, phase I trial. Lancet 369: 2097-2105.

Kearns CM, Gash DM. 1995. GDNF protects nigral dopamine neurons against 6-hydroxydopamine in vivo. Brain Res 672: 104-111.

Kettler R, Bartholini G, Pletscher A. 1974. In vivo enhancement of tyrosine hydroxylation in rat striatum by tetrahydrobiopterin. Nature 249: 476-478.

Khan NL, Brooks DJ, Pavese N, Sweeney MG, Wood NW, Lees AJ, Piccini P. 2002. Progression of nigrostriatal dysfunction in a parkin kindred: An [18F]dopa PET and clinical study. Brain 125: 2248-2256.

Kirik D, Rosenblad C, Björklund A. 2000. Preservation of a functional nigrostriatal dopamine pathway by GDNF in the intrastriatal 6-OHDA lesion model depends on the site of administration of the trophic factor. Eur J Neurosci 12: 3871-3882.

Kirik D, Georgievska B, Burger C, Winkler C, Muzyczka N, Mandel RJ, Bjorklund A. 2002. Reversal of motor impairments in parkinsonian rats by continuous intrastriatal delivery of L-dopa using rAAV-mediated gene transfer. Proc Natl Acad Sci 99: 4708-4713.

Kish SJ, Tong J, Hornykiewicz O, Rajput A, Chang L-J, Guttman M, Furukawa Y. 2008. Preferential loss of serotonin markers in caudate versus putamen in Parkinson's disease. Brain 131: 120-131.

Kishima H, Poyot T, Bloch J, Dauguet J, Condé F, Dollé F, Hinnen F, Pralong W, Palfi S, Déglon N, et al. 2004. Encapsulated GDNF-producing C2C12 cells for Parkinson's disease: A pre-clinical study in chronic MPTP-treated baboons. Neurobiol Dis 16: 428-439.

Kitada T, Asakawa S, Hattori N, Matsumine H, Yamamura Y, Minoshima S, Yokochi M, Mizuno Y, Shimizu N. 1998. Mutations in the parkin gene cause autosomal recessive juvenile parkinsonism. Nature 392: 605-608.

Kordower JH, Palfi S, Chen EY, Ma SY, Sendera T, Cochran EJ, Mufson EJ, Penn R, Goetz CG, Comella CD. 1999. Clinicopathological findings following intraventricular 
P. Coune et al.

glial-derived neurotrophic factor treatment in a patient with Parkinson's disease. Ann Neurol 46: 419-424.

Kordower JH, Emborg ME, Bloch J, Ma SY, Chu Y, Leventhal L, McBride J, Chen EY, Palfi S, Roitberg BZ, et al. 2000. Neurodegeneration prevented by lentiviral vector delivery of GDNF in primate models of Parkinson's disease. Science 290: 767-773.

Kordower JH, Herzog CD, Dass B, Bakay RAE, Stansell J, Gasmi M, Bartus RT. 2006. Delivery of neurturin by AAV2 (CERE-120)-mediated gene transfer provides structural and functional neuroprotection and neurorestoration in MPTP-treated monkeys. Ann Neurol 60: 706-715.

Kumar M, Keller B, Makalou N, Sutton RE. 2001. Systematic determination of the packaging limit of lentiviral vectors. Hum Gene Ther 12: 1893-1905.

Kwon I, Schaffer DV. 2008. Designer gene delivery vectors: Molecular engineering and evolution of adeno-associated viral vectors for enhanced gene transfer. Pharmaceut Res 25: 489-499.

Lee B, Lee H, Nam YR, Oh JH, Cho YH, Chang JW. 2005. Enhanced expression of glutamate decarboxylase $65 \mathrm{im}$ proves symptoms of rat parkinsonian models. Gene Therapy 12: $1215-1222$.

Leriche L, Björklund T, Breysse N, Besret L, Grégoire M-C, Carlsson T, Dollé F, Mandel RJ, Déglon N, Hantraye P, et al. 2009. Positron emission tomography imaging demonstrates correlation between behavioral recovery and correction of dopamine neurotransmission after gene therapy. J Neurosci 29: 1544-1553.

LeWitt PA, Rezai AR, Leehey MA, Ojemann SG, Flaherty AW, Eskandar EN, Kostyk SK, Thomas K, Sarkar A, Siddiqui MS. 2011. AAV2-GAD gene therapy for advanced Parkinson's disease: A double-blind, sham-surgery controlled, randomised trial. Lancet Neurol 10: 309-319.

Lim ST, Airavaara M, Harvey BK. 2010. Viral vectors for neurotrophic factor delivery: A gene therapy approach for neurodegenerative diseases of the CNS. Pharmacol Res 61: 14-26.

Lin LF, Doherty DH, Lile JD, Bektesh S, Collins F. 1993. GDNF: A glial cell line-derived neurotrophic factor for midbrain dopaminergic neurons. Science 260: 1130-1132.

Lo Bianco C, Déglon N, Pralong W, Aebischer P. 2004a. Lentiviral nigral delivery of GDNF does not prevent neurodegeneration in a genetic rat model of Parkinson's disease. Neurobiol Dis 17: 283-289.

Lo Bianco C, Schneider BL, Bauer M, Sajadi A, Brice A, Iwatsubo T, Aebischer P. 2004b. Lentiviral vector delivery of parkin prevents dopaminergic degeneration in an $\alpha$-synuclein rat model of Parkinson's disease. Proc Natl Acad Sci 101: $17510-17515$.

Luo J, Kaplitt MG, Fitzsimons HL, Zuzga DS, Liu Y, Oshinsky ML, During MJ. 2002. Subthalamic GAD gene therapy in a Parkinson's disease rat model. Science 298: 425-429.

Maersch S, Huber A, Büning H, Hallek M, Perabo L. 2010. Optimization of stealth adeno-associated virus vectors by randomization of immunogenic epitopes. Virology 397: $167-175$.

Manfredsson FP, Burger C, Sullivan LF, Muzyczka N, Lewin AS, Mandel RJ. 2007. rAAV-mediated nigral human parkin over-expression partially ameliorates motor deficits via enhanced dopamine neurotransmission in a rat model of Parkinson's disease. Exp Neurol 207: 289-301.

Maraganore DM, de Andrade M, Elbaz A, Farrer MJ, Ioannidis JP, Krüger R, Rocca WA, Schneider NK, Lesnick TG, Lincoln SJ, et al. 2006. Collaborative analysis of $\alpha$-synuclein gene promoter variability and Parkinson disease. JAMA 296: 661-670.

Marks WJ Jr, Ostrem JL, Verhagen L, Starr PA, Larson PS, Bakay RA, Taylor R, Cahn-Weiner DA, Stoessl AJ, Olanow CW. 2008. Safety and tolerability of intraputaminal delivery of CERE-120 (adeno-associated virus serotype 2-neurturin) to patients with idiopathic Parkinson's disease: An open-label, phase I trial. Lancet Neurol 7: 400-408.

Marks WJ Jr, Bartus RT, Siffert J, Davis CS, Lozano A, Boulis N, Vitek J, Stacy M, Turner D, Verhagen L. 2010. Gene delivery of AAV2-neurturin for Parkinson's disease: A double-blind, randomised, controlled trial. Lancet Neurol 9: 1164-1172.

McCormack AL, Mak SK, Henderson JM, Bumcrot D, Farrer MJ, Di Monte DA. 2010. $\alpha$-synuclein suppression by targeted small interfering RNA in the primate substantia nigra. PloS ONE 5: e12122.

Moffat M, Harmon S, Haycock J, O’Malley KL. 1997. LDopa and dopamine-producing gene cassettes for gene therapy approaches to Parkinson's disease. Exp Neurol 144: 69-73.

Montini E, Cesana D, Schmidt M, Sanvito F, Ponzoni M, Bartholomae C, Sergi Sergi L, Benedicenti F, Ambrosi A, Di Serio C, et al. 2006. Hematopoietic stem cell gene transfer in a tumor-prone mouse model uncovers low genotoxicity of lentiviral vector integration. Nat Biotechnol 24: 687-696.

Moskalenko M, Chen L, van Roey M, Donahue BA, Snyder RO, McArthur JG, Patel SD. 2000. Epitope mapping of human anti-adeno-associated virus Type 2 neutralizing antibodies: Implications for gene therapy and virus structure. J Virol 74: 1761-1766.

Muramatsu S-I, Fujimoto K-I, Ikeguchi K, Shizuma N, Kawasaki K, Ono F, Shen Y, Wang L, Mizukami H, Kume A, et al. 2002. Behavioral recovery in a primate model of Parkinson's disease by triple transduction of striatal cells with adeno-associated viral vectors expressing dopamine-synthesizing enzymes. Hum Gene Ther 13: $345-$ 354.

Naldini L, Blömer U, Gage FH, Trono D, Verma IM. 1996a. Efficient transfer, integration, and sustained long-term expression of the transgene in adult rat brains injected with a lentiviral vector. Proc Natl Acad Sci 93: 1138211388 .

Naldini L, Blömer U, Gallay P, Ory D, Mulligan R, Gage FH, Verma IM, Trono D. 1996b. In vivo gene delivery and stable transduction of nondividing cells by a lentiviral vector. Science 272: 263-267.

Narendra D, Tanaka A, Suen D-F, Youle RJ. 2008. Parkin is recruited selectively to impaired mitochondria and promotes their autophagy. J Cell Biol 183: 795-803.

Nishioka K, Hayashi S, Farrer MJ, Singleton AB, Yoshino H, Imai H, Kitami T, Sato K, Kuroda R, Tomiyama H, et al. 2006. Clinical heterogeneity of $\alpha$-synuclein gene duplication in Parkinson's disease. Ann Neurol 59: 298-309. 
Nutt JG, Burchiel KJ, Comella CL, Jankovic J, Lang AE, Laws ER, Lozano AM, Penn RD, Simpson RK, Stacy M, et al. 2003. Randomized, double-blind trial of glial cell linederived neurotrophic factor (GDNF) in PD. Neurology 60: $69-73$.

Olsen JC. 1998. Gene transfer vectors derived from equine infectious anemia virus. Gene Therapy 5: 1481-1487.

Palfi S, Leventhal L, Chu Y, Ma SY, Emborg M, Bakay R, Déglon N, Hantraye P, Aebischer P, Kordower JH. 2002. Lentivirally delivered glial cell line-derived neurotrophic factor increases the number of striatal dopaminergic neurons in primate models of nigrostriatal degeneration. $J$ Neurosci 22: 4942-4954.

Park K. 2001. Protection of nigral neurons by GDNF-engineered marrow cell transplantation. Neurosci Res 40: 315-323.

Pascual A, Hidalgo-Figueroa M, Piruat JI, Pintado CO, Gómez-Díaz R, López-Barneo J. 2008. Absolute requirement of GDNF for adult catecholaminergic neuron survival. Nat Neurosci 11: 755-761.

Paterna J-C, Feldon J, Büeler H. 2004. Transduction profiles of recombinant adeno-associated virus vectors derived from serotypes 2 and 5 in the nigrostriatal system of rats. J Virol 78: 6808-6817.

Paterna J-C, Leng A, Weber E, Feldon J, Büeler H. 2007. DJ-1 and Parkin modulate dopamine-dependent behavior and inhibit MPTP-induced nigral dopamine neuron loss in mice. Mol Ther 15: 698-704.

Rahim AA, Wong AMS, Howe SJ, Buckley SMK, AcostaSaltos AD, Elston KE, Ward NJ, Philpott NJ, Cooper JD, Anderson PN, et al. 2009. Efficient gene delivery to the adult and fetal CNS using pseudotyped nonintegrating lentiviral vectors. Gene Therapy 16: 509-520.

Rosenblad C, Kirik D, Devaux B, Moffat B, Phillips HS, Björklund A. 1999. Protection and regeneration of nigral dopaminergic neurons by neurturin or GDNF in a partial lesion model of Parkinson's disease after administration into the striatum or the lateral ventricle. Eur J Neurosci 11: $1554-1566$.

Sajadi A, Bensadoun J-C, Schneider BL, Lo Bianco C, Aebischer P. 2006. Transient striatal delivery of GDNF via encapsulated cells leads to sustained behavioral improvement in a bilateral model of Parkinson disease. Neurobiol Disease 22: 119-129.

Samulski RJ, Chang LS, Shenk T. 1989. Helper-free stocks of recombinant adeno-associated viruses: Normal integration does not require viral gene expression. J Virol 63 $3822-3828$.

Samulski RJ, Zhu X, Xiao X, Brook JD, Housman DE, Epstein N, Hunter LA. 1991. Targeted integration of adeno-associated virus (AAV) into human chromosome 19. EMBO J 10: 3941-3950.

Sapru MK, Yates JW, Hogan S, Jiang L, Halter J, Bohn MC. 2006. Silencing of human $\alpha$-synuclein in vitro and in rat brain using lentiviral-mediated RNAi. Exp Neurol 198: 382-390.

Sauer H, Rosenblad C, Björklund A. 1995. Glial cell linederived neurotrophic factor but not transforming growth factor $\beta 3$ prevents delayed degeneration of nigral dopa- minergic neurons following striatal 6-hydroxydopamine lesion. Proc Natl Acad Sci 92: 8935-8939.

Shen Y, Muramatsu SI, Ikeguchi K, Fujimoto KI, Fan DS, Ogawa M, Mizukami H, Urabe M, Kume A, Nagatsu I, et al. 2000. Triple transduction with adeno-associated virus vectors expressing tyrosine hydroxylase, aromaticL-amino-acid decarboxylase, and GTP cyclohydrolase I for gene therapy of Parkinson's disease. Hum Gene Ther 11: 1509-1519.

Shimura H, Hattori N, Kubo Si, Mizuno Y, Asakawa S, Minoshima S, Shimizu N, Iwai K, Chiba T, Tanaka K, et al. 2000. Familial Parkinson disease gene product, parkin, is a ubiquitin-protein ligase. Nat Gen 25: 302-305.

Singleton AB, Farrer M, Johnson J, Singleton A, Hague S, Kachergus J, Hulihan M, Peuralinna T, Dutra A, Nussbaum R, et al. 2003. $\alpha$-Synuclein locus triplication causes Parkinson's disease. Science 302: 841.

Soldner F, Hockemeyer D, Beard C, Gao Q, Bell GW, Cook EG, Hargus G, Blak A, Cooper O, Mitalipova M, et al. 2009. Parkinson's disease patient-derived induced pluripotent stem cells free of viral reprogramming factors. Cell 136: $964-977$.

Soldner F, Laganière J, Cheng AW, Hockemeyer D, Gao Q, Alagappan R, Khurana V, Golbe LI, Myers RH, Lindquist S, et al. 2011. Generation of isogenic pluripotent stem cells differing exclusively at two early onset Parkinson point mutations. Cell 146: 318-331.

Sun M, Zhang G-R, Kong L, Holmes C, Wang X, Zhang W, Goldstein DS, Geller AI. 2003. Correction of a rat model of Parkinson's disease by coexpression of tyrosine hydroxylase and aromatic amino acid decarboxylase from a helper virus-free herpes simplex virus type 1 vector. Hum Gene Ther 14: 415-424.

Tseng JL, Baetge EE, Zurn AD, Aebischer P. 1997. GDNF reduces drug-induced rotational behavior after medial forebrain bundle transection by a mechanism not involving striatal dopamine. J Neurosci 17: 325-333.

Vercammen L, Van der Perren A, Vaudano E, Gijsbers R, Debyser Z, Van den Haute C, Baekelandt V. 2006. Parkin protects against neurotoxicity in the 6-hydroxydopamine rat model for Parkinson's disease. Mol Ther 14: 716-723.

Yamada M, Mizuno Y, Mochizuki H. 2005. Parkin gene therapy for $\alpha$-synucleinopathy: A rat model of Parkinson's disease. Hum Gene Ther 16: 262-270.

Yang Y, Nishimura I, Imai Y, Takahashi R, Lu B. 2003. Parkin suppresses dopaminergic neuron-selective neurotoxicity induced by Pael-R in Drosophila. Neuron 37: 911-924.

Yasuda T, Miyachi S, Kitagawa R, Wada K, Nihira T, Ren Y-R, Hirai Y, Ageyama N, Terao K, Shimada T, et al. 2007. Neuronal specificity of $\alpha$-synuclein toxicity and effect of Parkin co-expression in primates. Neuroscience 144: $743-753$.

Zufferey R, Nagy D, Mandel RJ, Naldini L, Trono D. 1997. Multiply attenuated lentiviral vector achieves efficient gene delivery in vivo. Nat Biotechnol 15: 871-875.

Zufferey R, Dull T, Mandel RJ, Bukovsky A, Quiroz D, Naldini L, Trono D. 1998. Self-inactivating lentivirus vector for safe and efficient in vivo gene delivery. J Virol 72: 9873-9880. 


\section{$\&_{\mathrm{CSH}}^{\infty} \&$ Cold Spring Harbor

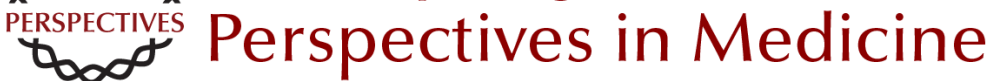

\section{Parkinson's Disease: Gene Therapies}

Philippe G. Coune, Bernard L. Schneider and Patrick Aebischer

Cold Spring Harb Perspect Med 2012; doi: 10.1101/cshperspect.a009431 originally published online January 18, 2012

\section{Subject Collection Parkinson's Disease}

Functional Neuroanatomy of the Basal Ganglia José L. Lanciego, Natasha Luquin and José A. Obeso

Animal Models of Parkinson's Disease: Vertebrate Genetics Yunjong Lee, Valina L. Dawson and Ted M. Dawson

Innate Inflammation in Parkinson's Disease V. Hugh Perry

Parkinson's Disease and Parkinsonism:

Neuropathology Dennis W. Dickson

Physiological Phenotype and Vulnerability in Parkinson's Disease

D. James Surmeier, Jaime N. Guzman, Javier Sanchez, et al.

Clinical Approach to Parkinson's Disease:

Features, Diagnosis, and Principles of Management João Massano and Kailash P. Bhatia

The Role of Autophagy in Parkinson's Disease Melinda A. Lynch-Day, Kai Mao, Ke Wang, et al.

Disruption of Protein Quality Control in Parkinson's Disease Casey Cook, Caroline Stetler and Leonard Petrucelli
Drosophila as a Model to Study Mitochondrial Dysfunction in Parkinson's Disease Ming Guo

Parkinsonism Due to Mutations in PINK1, Parkin, and DJ-1 and Oxidative Stress and Mitochondrial Pathways Mark R. Cookson

Programmed Cell Death in Parkinson's Disease Katerina Venderova and David S. Park

Genomics and Bioinformatics of Parkinson's

Disease Sonja W. Scholz, Tim Mhyre, Habtom Ressom, et al.

Motor Control Abnormalities in Parkinson's

Disease Pietro Mazzoni, Britne Shabbott and Juan Camilo Cortés

Parkinson's Disease: Gene Therapies Philippe G. Coune, Bernard L. Schneider and Patrick Aebischer

Functional Neuroimaging in Parkinson's Disease Martin Niethammer, Andrew Feigin and David Eidelberg

Leucine-Rich Repeat Kinase 2 for Beginners: Six Key Questions Lauren R. Kett and William T. Dauer

For additional articles in this collection, see http://perspectivesinmedicine.cshlp.org/cgi/collection/ 